\title{
The Safety and Efficacy of Sacral Neuromodulation on Refractory Urgency Urinary and Fecal Incontinence in Iraqi Patients
}

\author{
Mohammed Bassil Ismail ${ }^{1}$, Wameedh Qays Abdullhussein ${ }^{2}$ \\ ${ }^{1}$ CABMS (Urology), Urology Department, College of Medicine, University of Baghdad, \\ ${ }^{2}$ CABMS (Neurosurgery), Medical City Complex, Baghdad
}

\begin{abstract}
Background: Urinary urgency incontinence is characterized by symptoms of involuntary loss of urine that preceded or accompanied by sudden desire to void. Fecal incontinence is defined as involuntary passage of stool through the anus. It may vary from soiling to complete evacuation. This involuntary loss of feces, flatus or urge incontinence adversely affects quality of life.
\end{abstract}

Objectives: To evaluate the efficacy and safety of sacral neuromodulation on these pathologies.

Method: Following a detailed investigation, 21 patients with either urinary incontinence, or both urinary and fecal, who did not respond to medical and behavioral treatment were offered the sacral neuromodulation therapy and followed for at least 12 months post implant regarding response and development of complication if any found.

Results: In the period from November 2015 to May 2017. The unit of neurogenic bladder and neuromodulation in surgical subspecialty hospital, medical city complex had implanted 21 Patients with urinary incontinence were using from (4-17) pads/day (mean of 10.5/day) presacral neuromodulation which were declined significantly to (0-3) pads/day (mean of 2.2/day).

From the eighteen patients who presented with fecal incontinence after the implantation of sacral neuromodulation interstim 11 permanent devices only four remained incontinent .and from the nine patients who presented with erectile dysfunction only two remained impotent.

Conclusion: The use of Sacral Neuromodulation in Iraqi patients with Urinary and Fecal Incontinence is safe and effective

Keywords: Sacral Neuromodulation, Urgency urinary incontinence, fecal incontinence.

\section{Introduction}

Sacral neuromodulation (SNM) is considered now a well-accepted tertiary treatment modality for patients complaining from refractory nonneurogenic bladder symptoms and nonobstructive urinary retention. ${ }^{(1)}$

Sacral neuromodulation was FDA approved for the treatment of urgency urinary incontinence since $1997 .^{(2)}$

Its exact action mechanism is not fully defined, but it most likely involves the electrical modulation and reset of neuronal reflexes and voiding center through peripheral afferents and not stimulating the detrusor bladder muscle or urethral internal or external sphincter directly. ${ }^{(3-4)}$

SNM is very effective in the management of many urological diseases refractory to medical therapy, like frequency-urgency syndrome, nonobstructive urinary retention, neurogenic bladder, and others. Sacral neuromodulation has been FDA-approved as proven effective treatment modality for the management of fecal incontinence in 2011. ${ }^{(5)}$ 
It modulates the spinal cord reflexes that affect the bladder, urethra, anal sphincter and pelvic floor muscle. $^{(6)}$

Urgency urinary incontinence (UUI) is defined as involuntary loss of urine that precede or accompanied by sudden desire to void. Urgency incontinence is considered refractory when shows no response to behavioral therapies and at least two medications. ${ }^{(7)}$ The prevalence of urgency urinary incontinence increases with age. ${ }^{(8)}$

Fecal incontinence is a humiliating life-altering condition that affects nearly $2 \%$ of population. ${ }^{(10)}$

\section{Patient and Method}

A prospective cohort study was conducted in a tertiary referral specialized neuromodulation unit to assess the efficacy of SNM in patients with refractory urinary and fecal incontinence. All patients between 16 and 61 years of age, who were referred to surgical subspecialty hospital, medical city complex complaining from Urinaryand Fecal Incontinence refractory to conservative treatment, were eligible to be included in this study. Informed consent was obtained from all patients and first-degree relatives.

Full detailed history and prior treatments were collected from them, full physical examination was done 3 days voiding diary.

Further diagnostic tests included urinalysis, abdomino-pelvic ultrasound, renal function test, full urodynamics, lumbosacral MRI, flexible cystoscopy was done to all patients.

All those patients should have urinary incontinence alone or associated with fecal incontinence According to guidelines both American and European offered conservative treatment for at least 8-12 weeks if failed so, Refractory incontinence was considered with persistence of symptoms despite at least one supervised behavioral or medical therapy or both for at least 8-12 weeks.

\section{Exclusion Criteria:}

1. Patients with urinary incontinence due to intrinsic sphincteric deficiency.

2. urinary incontinence due to anatomical abnormality like ectopic ureter of vesicovaginal fistulae
3. Patient age less than 16 years.

4. Patients who had less than $50 \%$ improvement in their symptoms during temporary stimulation phase.

5. Patients with pure fecal incontinence (we do not have the facility to exclude abnormality in the anal sphincter)

Those patients were offered sacral neuromodulation in two stage surgery in the first-stage tined lead placement in S3 foramen under fluoroscopic examination. Both motor and sensory responses were assessed for all electrodes independently if there is good response the lead will place and connected to external temporary device. During the two weeks of testing phase, patients will be followed by 3 days voiding diary and full bladder pelvic ultrasound programs will be changed by the surgeon to optimize good results. Patients with more than $50 \%$ response were considered as responders and permanent device was implanted for them.

Scheduled visits postimplant from the patients to the outpatient after two weeks and the programmed, every 3 months for at least 4 or 5 times for at least one year and inquire about any undesirable side effects.

\section{Results}

In the period from November 2015 to May 2017 the unit of neurogenic bladder and neuromodulation in surgical subspecialty hospital, medical city complex had implanted 21 permanent interstim II devices in 21 patients with age ranging from 16 to 61 (table 1) year old complaining from urgency urinary incontinence 18 patients had also associated fecal incontinence, and nine of them had erectile dysfunction also. all the patients were followed for at least one-year post implantation.

Table 1: Descriptive characteristics of studied sample

\begin{tabular}{|l|l|c|c|}
\hline \multicolumn{2}{|c|}{} & No. & $\%$ \\
\hline \multirow{2}{*}{$\begin{array}{l}\text { Age } \\
\text { groups }\end{array}$} & $<40$ year & 16 & $76.2 \%$ \\
\cline { 2 - 4 } & $=>40$ year & 5 & $23.8 \%$ \\
\hline \multirow{2}{*}{ Gender } & Male & 12 & $57.1 \%$ \\
\cline { 2 - 4 } & Female & 9 & $42.9 \%$ \\
\hline Diagnosis & Urgency incontinence & 21 & $100 \%$ \\
\hline
\end{tabular}

Patients with urinary incontinence were using from (4-17) pads/day (mean of 10.5/day) presacral neuromodulation which were declined significantly to (0-3) pads/day (mean of 2.2/day). (Table 2, table 3). 
Table 2: Mean number of pads pre and post SNS

\begin{tabular}{|l|c|c|c|c|}
\hline \multicolumn{4}{|c|}{ Paired Samples Statistics } & \multirow{2}{*}{ p-value } \\
\cline { 1 - 3 } No. of pads/day & Mean & Std. Deviation & Mean difference & \multirow{2}{*}{0.001} \\
\hline Pre & 10.5 & 3.5 & 8.3 & \\
\hline Post & 2.2 & 1.6 & & \\
\hline
\end{tabular}

Table 3: Number of pre and post pads according to number of patients

\begin{tabular}{|c|c|c|c|c|c|c|c|c|c|c|c|c|c|}
\hline \multirow{3}{*}{$\begin{array}{l}\text { No. of } \\
\text { patients }\end{array}$} & \multirow{3}{*}{$\begin{array}{c}\text { No. of } \\
\text { pads/day } \\
\text { pre-sns }\end{array}$} & \multicolumn{12}{|c|}{ No. of pads/day post-sns } \\
\hline & & \multicolumn{2}{|c|}{$\mathbf{0}$} & \multicolumn{2}{|c|}{1} & \multicolumn{2}{|c|}{2} & \multicolumn{2}{|c|}{3} & \multicolumn{2}{|c|}{4} & \multicolumn{2}{|c|}{5} \\
\hline & & No. & $\%$ & No. & $\%$ & No. & $\%$ & No. & $\%$ & No. & $\%$ & No. & $\%$ \\
\hline 1 & 4 & 1 & $100.0 \%$ & 0 & $0.0 \%$ & 0 & $0.0 \%$ & 0 & $0.0 \%$ & 0 & $0.0 \%$ & 0 & $0.0 \%$ \\
\hline 1 & 5 & 1 & $100.0 \%$ & 0 & $0.0 \%$ & 0 & $0.0 \%$ & 0 & $0.0 \%$ & 0 & $0.0 \%$ & 0 & $0.0 \%$ \\
\hline 2 & 6 & 1 & $50.0 \%$ & 1 & $50.0 \%$ & 0 & $0.0 \%$ & 0 & $0.0 \%$ & 0 & $0.0 \%$ & 0 & $0.0 \%$ \\
\hline 1 & 7 & 1 & $100.0 \%$ & 0 & $0.0 \%$ & 0 & $0.0 \%$ & 0 & $0.0 \%$ & 0 & $0.0 \%$ & 0 & $0.0 \%$ \\
\hline 1 & 8 & 0 & $0.0 \%$ & 0 & $0.0 \%$ & 1 & $100.0 \%$ & 0 & $0.0 \%$ & 0 & $0.0 \%$ & 0 & $0.0 \%$ \\
\hline 4 & 10 & 0 & $0.0 \%$ & 0 & $0.0 \%$ & 3 & $75.0 \%$ & 1 & $25.0 \%$ & 0 & $0.0 \%$ & 0 & $0.0 \%$ \\
\hline 3 & 11 & 0 & $0.0 \%$ & 0 & $0.0 \%$ & 2 & $66.7 \%$ & 0 & $0.0 \%$ & 1 & $33.3 \%$ & 0 & $0.0 \%$ \\
\hline 2 & 12 & 0 & $0.0 \%$ & 0 & $0.0 \%$ & 0 & $0.0 \%$ & 1 & $50.0 \%$ & 0 & $0.0 \%$ & 1 & $50.0 \%$ \\
\hline 2 & 13 & 1 & $50.0 \%$ & 0 & $0.0 \%$ & 1 & $50.0 \%$ & 0 & $0.0 \%$ & 0 & $0.0 \%$ & 0 & $0.0 \%$ \\
\hline 1 & 14 & 0 & $0.0 \%$ & 0 & $0.0 \%$ & 0 & $0.0 \%$ & 0 & $0.0 \%$ & 1 & $100.0 \%$ & 0 & $0.0 \%$ \\
\hline 2 & 15 & 0 & $0.0 \%$ & 0 & $0.0 \%$ & 0 & $0.0 \%$ & 1 & $50.0 \%$ & 1 & $50.0 \%$ & 0 & $0.0 \%$ \\
\hline 1 & 17 & 0 & $0.0 \%$ & 0 & $0.0 \%$ & 0 & $0.0 \%$ & 0 & $0.0 \%$ & 0 & $0.0 \%$ & 1 & $100.0 \%$ \\
\hline
\end{tabular}

From the eighteen patients who presented with fecal incontinence after the implantation of sacral neuromodulation interstim 11 permanent devices only four remained incontinent and from the nine patients who presented with erectile dysfunction only two remained impotent (nearly all those patients didn't even mention this complaint primarily may be due to that their incomitance where their major complaint or maybe they were embarrassed). (Table 5).

From the twenty-one patients treated by sacral neuromodulatin two patients had simple pain at the site of implantation some time radiating to their legs treated by reprograming of the device and simple analgesia. One patient had device infection and another had device malfunction due to direct trauma to the device treated by removal of the device and reimplantation of another device in the contralateral site. (table 4)
Table 4: Frequency of complications post SNS

\begin{tabular}{|l|c|c|}
\hline & No. & \% \\
\hline Nill & 17 & 81.0 \\
\hline Simple pain & 2 & 9.5 \\
\hline Device infection & 1 & 4.8 \\
\hline Device malfunction & 1 & 4.8 \\
\hline Total & $\mathbf{2 1}$ & $\mathbf{1 0 0 . 0}$ \\
\hline
\end{tabular}

Table 5: Status of incontinent and ED pre and post SNS N=21

\begin{tabular}{|c|c|c|c|}
\hline & & No. & $\%$ \\
\hline \multicolumn{4}{|c|}{ Bowel status } \\
\hline \multirow{2}{*}{ Incontinent } & Pre-sns & 18 & $85.7 \%$ \\
\hline & post-sns & 4 & $19.0 \%$ \\
\hline \multicolumn{4}{|c|}{ Potency status } \\
\hline \multirow{2}{*}{$\mathrm{Ed}$} & pre-sns & 9 & $64.3 \%$ \\
\hline & Post-sns & 2 & $14.3 \%$ \\
\hline
\end{tabular}




\section{Discussion}

Sacral neuromodulation (SNM) is proved to a valuable addition to urology as an option for the treatment of patients with refractory urgency frequency syndrome whether dry or wet, and urinary retention or non-obstructive unresponsive to behavioral and medical treatment. ${ }^{(11)}$

Sacral neuromodulation is an attractive treatment modality because of its minimally-invasive approach. ${ }^{(12)}$

Although sacral neuromodulation is very effective in patients with sphincteric defect, its action is thought to be extrasphincteric. It has been suggested to act centrally through spinal afferents. ${ }^{(13)}$

The impact of SNM on anorectal physiology was variable. However, there appeared to be a trend towards improved anal pressures (as evidenced by increased resting and maximum squeeze pressures) and rectal sensitivity (as evidenced by a decrease in sensory threshold volumes). ${ }^{(14)}$

In addition, it has been suggested that SNM creates a change in the colonic activity a 'physiological brake' so prevents the delivery of stool to the anorectal unit that is functionally suboptimal and thus reduces fecal incontinence. ${ }^{(15)}$

SNM may modulate the higher voiding center reflex pathways by resting the balance between the excitatory and the inhibitory fibers of the bladder. ${ }^{(16)}$

In our study we offered sacral neuromodulation via implantation of interstim II devices to twenty one patients with refractory urgency urinary incontinence, eighteen one of them complaining from fecal incontinence, nine of them complaining from erectile dysfunction.

After at least one year follow up post sacral neuromodulation for the patients there was a significant decrease in the number of pads used by the patients (mean preSNM10.5, meanpostSNM 2.2). Only four patients from the eighteen complaining from fecal incontinence remained incontinent seven from the nine patients with erectile dysfunction became potent again.

No serious complication faced by the patients during or following SNM for at least one year . 17 patient had nil complication.

Several studies have demonstrated the efficacy of SNM on both urinary and fecal incontinence for the short and long term which has results approximates to our own.

Van Kerrebroeck et al showed that there was a decrease in the episodes of urgency urinary incontinence from 9.6 preSNM to 4.7 at 1 -year postSNM. The number of pads/daypostSNM decreased to 1.8 from 5 pads/day preSNM at 5-year follow-up. ${ }^{(17)}$

Maeda et al showed $42.6 \%$ favorable outcome of sacral neuromodulation in patients with fecal incontinence after 60 months of follow up. ${ }^{(18)}$

In conclusion according to above results we believe that Sacral Neuromodulation is safe and effective method of treatment in refractory urgency urinary and fecal incontinence.

\section{References}

1. Peripheral and Sacral Neuromodulation in the Treatment of Neurogenic Lower Urinary Tract Dysfunction Paholo $G$ et al Urol Clin N Am 44 (2017) 453-461.

2. Bolton JF, Harrison SC. Neuromodulation 10 years on: how widely should we use this technique in bladder dysfunction? Current opinion in urology. 2009; 19(4):375-9.

3. Jonas U, Fowler CJ, Chancellor MB et al. Efficacy of sacral nerve stimulation for urinary retention: results 18 months after implantation. J. Urol. 2001; 165: 15-19.

4. Sutherland SE, Lavers A, Carlson A, Holtz C, Kesha J, Siegel SW. Sacral nerve stimulation for voiding dysfunction: one institution's 11-year experience.NeururolUrodyn. 2007; 26: 19-28.

5. Mirbagheri N, Sivakumaran Y, Nassar N, Gladman MA. Systematic review of the impact of sacral neuromodulation on clinical symptoms and gastrointestinal physiology. ANZ J Surg. 2015

6. Tjandra JJ, Chan MK, Yeh CH, Murray-Green C. Sacral nerve stimulation is more effective than optimal medical therapy for severe fecal incontinence: a randomized, controlled study. Dis Colon Rectum 2008; 51: 494-502.

7. Willis-Gray MG, Dieter AA, Geller EJ. Evaluation and management of overactive bladder: strategies for optimizing care. Res Rep Urol. 2016; 8:113-12. [PubMed: 27556018]

8. Stewart WF, Van Rooyen JB, Cundiff GW, et al. 
Prevalence and burden of overactive bladder in the United States. World J Urol. 2003; 20:327-336. [PubMed: 12811491]

9. Kraus SR, Bavendam T, Brake T, et al. Vulnerable Elderly Patients and Overactive Bladder Syndrome. Drugs Aging. 2010; 27(9):697-713. [PubMed: 20809661]

10. Nelson RN, Norton EC, Furner. S Communitybased prevalence of anal incontinence. JAMA 1995; 274: 559-61.

11. Bartley J, Gilleran J, Peters K. Neuromodulation for overactive bladder. Nat.Rev. Urol. 2013; 10: 513-21.

12. Gotoh M, Yamamoto T, Kato M et al. Regenerative treatment of male stress urinary incontinence by periurethral injection of autologous adiposederived regenerative cells: 1-year outcomes in 11 patients. Int. J. Urol. 2014; 21: 294-300.

13. Carrington EV, Evers J, Grossi U etal. A systematic review of sacral nerve stimulation mechanisms in the treatment of fecal incontinence and constipation. Neurogastroenterol. Motil. 2014; 26: 1222- 1237.
14. Naseem Mirbagheri et al Systematic review of the impact of sacral neuromodulation on clinical symptoms and gastrointestinal physiology. ANZ j surg 86(2016)232-236.

15. Patton V, Wiklendt L, Arkwright JW, Lubowski DZ, Dinning PG. The effect of sacral nerve stimulation on distal colonic motility in patients with faecal incontinence. Br. J. Surg. 2013; 100: 959-968.

16. Burks FN, Bui DT, Peters KM. Neuromodulation and the neurogenic bladder. Urol Clin North Am 2010;37:559-65.

17. Van KerrebroeckPE, van Voskuilen AC,Heesakkers JP, et al. Results of sacral neuromodulation therapy for urinary voiding dysfunction: outcomes of a prospective, worldwide clinical study. J Urol. 2007;178(5):2029-2034.

18. Maeda Y, Lundby L, Buntzen S, Laurberg S. Outcome of sacral nerve stimulation for fecal incontinence at 5 years. Ann Surg 2013; 259 (6): 1126-31. 